\title{
Poverty And Vulnerability To Poverty: Conceptual Overview, Measurements And Causes
}

\author{
Zrakpa Melaine OUOYA \\ University Felix Houphouet Boigny of Abidjan \\ Doctoral School of Economics and Management Department (UFRSEG) \\ DOI: 10.29322/IJSRP.11.08.2021.p11649 \\ http://dx.doi.org/10.29322/IJSRP.11.08.2021.p11649
}

\begin{abstract}
Poverty and vulnerability to poverty are two concepts measuring the same economic reality at different time horizons. While the first is measured ex-post, the second relates to an ex-ante measurement. We first attempt to identify the different approaches of poverty analysis. From the work of Ruggeri Laderchi et al. (2003) on the multidimensional approach to poverty, Carr (2008) traces an intermediate path between the absolutes of universalizing approaches and the tendencies to atomize basic approaches to the understanding of poverty / poverties. He thus assigns a role to local knowledge, external expertise and the practitioner's development perspective to build the basic critical approach to development. We fund that economic literature measures poverty according to subjective and objective point of view. Three subjective approaches are identified namely the relative deprivation approach, the consensus approach and the capability approach which understands poverty and well-being in terms of human capacities or opportunities to achieve positive freedoms. The objective measure of poverty that overcomes the limitations of all the previous measurements (counting ratio and intensity of poverty) is that based on the pioneering work of Sen (1976) and developed by Foster, Greer, and Thorbecke (1984).
\end{abstract}

\section{INTRODUCTION}

$\mathbf{N}$ obel laureate in economics Schultz (1980) puts agriculture and the poor at the center of the global economy by revealing: "Most people in the world are poor, so if we knew about the economy of being poor we will know much of the economy that really matters. Most of the world's poor make a living from farming, so if we knew about the economics of farming we would know much of economics of being poor. " Poverty reduction remains the backbone and the main technical aspect of all development policies around the world. To ensure that it is properly taken into account, much work has been carried out by researchers to either measure poverty or identify the factors that may influence it. Like many other concepts emanating from the study of poverty, the recent decades have seen the emergence of the study of vulnerability to poverty in the economic literature. Through this study, we want to make an overview of this literature dealing on the one hand with poverty, on the other hand, with vulnerability to poverty.

This review will be done in three sections: the first section will be devoted to a review of the study of poverty and will take into account three subsections. The second section
Vulnerability to poverty is the likelihood that a non-poor (or poor) household will fall (or will remain) in poverty in the near future. It is mainly the presence of risk in the daily life of these households and their low capacity to cope with these risks and the shocks they could generate that explain this state of vulnerability. The economic literature identifies four distinct approaches to analyzing household vulnerability to poverty namely the income or consumption approach, the asset approach, the livelihood approach and the capability approach. We identify three main instruments to assess vulnerability namely the vulnerability as expected poverty (VEP), the vulnerability as low expected utility (VEU) and the vulnerability as uncovered exposure to risks (VER). The message here is that identifying those who are poor now is an inadequate indicator of those who should be poor in the future. Households change their poverty status from one year to an other due to risks they face in their daily lives. Thus, implementing sustainable poverty alleviation strategies requires taking into account the poor and the vulnerable to poverty.

Keywords : Poverty, vulnerability to poverty, measurements, causes

relates to the concept of vulnerability to poverty and will include four subsections. The last section will be devoted to the conclusion of our work.

\section{CONCEPT OF POVERTY}

Poverty is a concept that has been the subject of many scientific works. From its conceptual analysis to its measurement, including the identification of its analytical approaches, poverty has been the subject of particular interest by researchers. It will be a question here of making a brief history of the concept of poverty then to identify the analytical approaches of poverty. We will then present the measurement's tools and the structural causes of poverty. In the last subsection, we will deal with the presentation of a very widespread poverty reduction strategy.

\section{Brief History And Axes Of Understanding Of Poverty}

Rowntree (1901) was the first to develop a poverty standard for individual families. In the $1960 \mathrm{~s}$, the assessment of the level of poverty was based on the level of income, reflected by macroeconomic indicators such as GNP per capita. 
Following the pioneering work of the mid-1970s of the International Labor Organization (ILO), poverty is no longer defined only as a lack of income, but also as a lack of access to health, education and to other services.

In the 1980s, new lines of research were added to the study of poverty. The main innovations were: (a) the incorporation of non-monetary aspects; (b) a new interest in vulnerability and its counterparts, security associated with a better understanding of seasonality and the impact of shocks; (c) a broadening of the framework for studying poverty by taking into account other concepts such as means of subsistence ... a greater consideration of the study of gender.

An understanding of poverty in both its singular and universal forms approaches the identification and measurement of poverty in three ways. First of all, in our efforts to reduce poverty, we tend to rely on preconceptions of poverty and its solutions. Thus, Azam et al. (2009) can argue that "growth" or "access to capital" (eg De Soto 2000) is the basis of a comprehensive solution to poverty. Second, because poverty is often seen as the same everywhere and therefore capable of being addressed through known sets of interventions, there is little impetus to understand how people living in particular places come to identify poverty (if, indeed, such a concept exists locally) and how they approach the problems they qualify as poverty. Finally, treating poverty as a singular and universal problem leads to difficulties in identifying the trade-offs and synergies that characterize any poverty reduction intervention. From this point of view, it is necessary to identify poverty analysis approaches and that will be done into the second sub-section.

\section{Poverty Analysis Approaches}

We identify two approaches to analyzing poverty, namely the multidimensional approach and the basic critical approach to development.

The multidimensional approach comes from the work of Ruggeri Laderchi et al., (2003) who summarizes the common problems encountered when defining and / or measuring poverty under eight headings: (1) The sphere of concern in which poverty is defined; (2) the applicability of the measures or definitions to all societies; (3) the objective or subjective nature of the methods used to identify and measure poverty; (4) the particular or universal character of poverty lines; (5) the question of the unit of measurement (individual, household, village, nation); (6) the method of dealing with the multidimensionality of poverty; (7) the time horizon for identifying and measuring poverty; And (8) the extent to which a definition of poverty provides (or should provide) a causal explanation for poverty.

For Carr (2008), the question of the sphere of interest only materializes if we assume that we cannot redefine this sphere in different contexts. The questions of poverty lines, unit of measurement and time horizon only become problems if we seek the only real poverty line, unit of measurement or time horizon, valid in all contexts. So, according to Carr (2008), whether it is multidimensionality, objectivity or subjectivity of methods and definitions and even causality, it is simply this universalizing impulse instead of a particularist apprehension which gives rise to tensions in the analysis and definition of poverty.
While perhaps recognizing as interconnected the different issues at which the fight against poverty is directed (for example, recognizing that fertility, education, income and environmental quality are in many ways interdependent), current approaches to poverty use interventions most often designed in a sectoral way because it is assumed that sectoral approaches work in synergy in solving a common problem. Such efforts, while aimed at solving a general underlying problem, often fail to capture the trade-offs and mutual benefits of these interrelationships. In short, without addressing the local multidimensionality of what we call poverty, our interventions can cause more difficulties than they alleviate (Carr, 2008).

It is following this analysis that Carr (2008) traces an intermediate path between the absolutes of universalizing approaches and the tendencies to atomize basic approaches to the understanding of poverty / poverties. The basic critical approach to development assigns a role to both local knowledge, external expertise and the practitioner's development perspective. This approach will also need to answer three key questions: (1) Who wins and who loses from existing definitions of problems and their solutions? (2) Who do identify these problems and their solutions? And (3) How do these solutions become legitimate in a particular social unit, when their benefits are not evenly distributed across the unit? This critical grassroots perspective recognizes that while we are to continue to value local voices in development practice, we must also recognize that the solutions these local voices present to us may not lead us to alleviate barriers to human well-being in some particular contexts. A basic critical approach allows the development practitioner to examine local strategies for addressing barriers to human well-being in a way that elucidates both the material and socio-cultural outcomes of existing strategies. Following this presentation, we direct our argumentation towards tools for measuring poverty.

\section{Poverty Measurement}

The economic literature identifies two dominant types of approaches to measuring poverty: subjective approaches based on individuals' perseptions of their poverty status and objective approaches, based mainly on the pioneering work of Sen (1981). We will first present the subjective approaches and their limitations before focusing on the objective approaches.

\section{Subjective Instruments For Measuring Poverty}

Here we identify three subjective approaches to measuring poverty, namely the relative deprivation approach, the consensus approach and the capability approach.

The first approach to analyzing subjective poverty is indeed that based on the concept of relative 'deprivation' developed by Peter Townsend in England. According to Townsend, "Individuals, families or groups of the population may be considered poor when they lack the necessary resources to obtain the typical diet, the participation in activities, and to have the living conditions and amenities that are necessary usual, or at least widely encouraged or approved in the societies to which they belong. Their resources are so significantly lower than those determined by the average individual or family that they are, in fact, excluded from 
everyday lifestyles, habits and ordinary activities. ". (Townsend, 1979: 31)

This approach is part of the gradual shift from a physiological model of poverty, based on the non-satisfaction of essential physical and material needs, to a sociological model taking into account the social needs of individuals, such as those relating to participation in society (Shaffer, 2007). Using this methodology usually involves several steps. First, focus groups are organized (Pantazis et al, 2006a) in which a representative sample of people is invited to indicate which everyday consumer goods and activities they consider to be necessities of life (i.e. that is, no household or family should be deprived of it). The goods and activities considered as such by more than half of the people questioned are then retained, and the participants are then invited to specify, either in the same survey or in a separate survey, whether they themselves have these different items. If this is not the case, they must then specify whether it is a choice (they do not want it) or a lack of resources (they do not have the means). The items considered as necessities by a majority of individuals then form the basis of a deprivation index. According to this index, individuals who, due to the unavailability of resources, do not have the goods considered as necessities receive (for each good) a score of 1 (private) or 0 (not private). Townsend has shown that multiple deprivations are strongly correlated with income poverty, and that below a certain level of income (or resources), the number of deprivations experienced increases rapidly (Townsend, 1979). It is at this point, between two and four deprivations (depending on the studies) that a threshold can be set between poor and non-poor (or between those who experience deprivation and others). Following this approach developed by Townsend (1979), we orient our argument towards the consensual approach to measuring poverty.

The "consensual" approach is based on a consensual vision of the definition of the necessities of life. Here, poverty is defined on the basis of a consensus between several actors to identify the basic elements from which to distinguish between poor and non-poor.Ccriticism has been raised against the tendency of poverty surveys to rely primarily on the opinions of experts (academics, social workers, etc.), and never or rarely to integrate those of the rest of the population, especially the perceptions of those who have direct experience of poverty, ie the poor themselves (Citro and Michael, 1995). It is against this tendency that British researchers Mack and Lansley (1985) developed the consensus approach to defining "basic necessities of life". This gives a central place to the perception of individuals of their social situation and their own needs in the definition and measurement of poverty. Building on Townsend's concept of relative deprivation, Mack and Lansley (1985) have developed methods to determine consensually what constitutes a decent standard of living for individuals.

This approach measures poverty by probing public perceptions of basic needs through a representative survey. Also Nandy et al., (2016) suggests in their work that the idea according to which adaptive preferences (which would lead the poorest to underestimate their needs) would represent an important limit to the effectiveness of the consensus approach was unfounded. In their analysis of Benin, they found that there is not only a clear consensus among all social groups as to the importance of all elements, but they also observe that poor people are more likely than others to consider each of the constituent elements of the deprivation index as indispensable.

While the question of how to measure poverty in terms of income and consumer goods persists, economists and other social scientists have increasingly recognized the need to broaden conceptions of poverty and development. These questions helped to show the importance of 'growth and redistribution' and the basic needs approach to development in the 1970s and later in the 1980s (see Stewart, 2000). They created momentum for the social indicators movement. Increasingly, the intensity of this movement has shifted from securing the means used to eliminate poverty and achieve development objectives (employment, equitable growth, access to basic goods and services) towards promoting the goal of human development.

The shift from the focus of the means to the end has allowed the development of the capability approach pioneered by Nobel Prize winner Amartya Sen (see Sen, 1980, 1984, 1985).

The central argument behind the capability approach is that the standard economic approach to well-being - based on utility or access to resources - excludes much relevant information and provides unreliable guides to poverty and well-being. The solution to this problem is to understand poverty and well-being in terms of human capacities or opportunities to achieve positive freedoms such as being able to live long, be well nourished, be literate, take part to community life and achieve self-esteem. Seasonality of income, consumption, and access to food are some of the focus of the annual cycle of food deprivation and hunger that occurs in many rural settings (Chambers et al., 1981). The significance of specific experiences of poverty at certain points in life has also been elucidated with a particular emphasis on access to food for pregnant women and children and education. For instance, a lack of access to food, basic health services or education from an early age (fetal and child condition) can have irreversible effects on the physical status and cognitive capacity of the individual (Yaqub , 2002 cited by Clark et al., 2010).

Following the presentation of these subjectives approaches, it is appropriate to consider certain criticisms which are sometimes expressed against methods based on theses subjective measurements of poverty. In particular, an issue often raised about individuals' subjective perceptions of their own social position and well-being is that of "adaptive preferences". According to this theory, poor or disadvantaged people can adapt their preferences to the possibilities available to them, and these limited horizons mean that they can estimate downwards what the necessities of life are in a given society. In other words, according to Nussbaum, "The desires and preferences of individuals adjust to their beliefs about social norms and their own possibilities. Thus, individuals generally adjust their preferences to reflect their level of available possibilities... Individuals in groups that have not persistent access to education or employment outside the home may take a long time to desire these things because they do not know if they need it or in which way that will be useful in a life like theirs "(Nussbaum, 1999). People experiencing poverty (and deprivation) would therefore be less likely to demand radical changes or standards rising to the level of norms established by 
experts, and would accept their situation out of necessity (Sen, 1992). For some, this phenomenon introduces a bias into the subjective measure of poverty, in that it results in a limited expression of what social norms actually are or should be, affecting the reliability of measures based on individuals' perceptions. This situation leaves room for more objective approaches to express themselves better in the environment of the study of poverty.

\section{Objective Instruments For Measuring Poverty}

Objective poverty measures all incorporate the total number of individuals and therefore depend on the identification of a poverty line. The poverty line is defined as the monetary threshold of the level of well-being of a given individual in a given space at a given time. Individuals below this level of well-being are considered poor and the others are not. Selecting an appropriate poverty line raises a series of practical and methodological challenges (Ravallion, 1998). A simple approach would be to derive the poverty lines from the estimate of minimum nutritional requirements 'or consumption standards' for a particular society. This approach, however, does not take into account the fact that nutritional requirements and commodity requirements can vary widely both within and between countries. There are also difficulties in defining these requirements, which depend on the choice of commodities and the assumption about the proportion of income used for food expenditure (Sen, 1981, pp. 11-14).

One way to solve this problem is to identify more than one poverty line. This technique has been used very effectively to distinguish categories such as the moderate poor ', and extreme poor' in Bangladesh and 'poor 'and 'very poor' in South Africa (Rahman and Hossian, 1995). A more sophisticated approach however involves taking into account vagueness or imprecision in defining the poverty line. Cerioli and Zani (1990) for example allow the specification of a continuous series of poverty lines and rank the poor according to their level of disadvantage. Following the definition of the poverty line, the question of how to measure poverty arises.

Given the choice of a particular poverty line basis and a scaling procedure (in other words, given the choice of a poverty line sample), measuring poverty involves the choice of method to describe the extent of poverty within the population.

The most obvious approach is simply to count the number of poor households with incomes less than the appropriate poverty lines. Poverty is measure as a simple counting ratio (in other words $q / n$ where $q$ is the number of poor households and $n$ the total number of households) which however says nothing about the depth of poverty. This first measure gives no information on the extent and magnitude of the shortfall below the poverty line. Thus, a reduction in the income of anyone below the poverty line will leave this measure unchanged, ceteris paribus (Sen, 1981, p. 11). For this reason, this ratio is often supplemented by the income gap. Calculate the average poverty gap (in other words $1 / q \sum_{i=1}^{q}\left(z_{i}-y_{i}\right)$ where $y_{i}$ is household income and $z_{i}$ is the appropriate poverty line for households) can solve this problem and is an intuitively attractive approach to measuring the extent of poverty.

Unfortunately, according to Sen (1976), the measure of poverty derived from the poverty intensity approach has the relative flaw in that it does not take into account the number of poor households in the economy, and there is no increase in poverty if a poorer household transfers income to a less poor household. Finally, neither the counting of the poor, nor the measurement of poverty by the intensity of poverty is sensitive to the distribution of income among poor households.

Sen (1976) attempts to design a more satisfactory poverty index which has generated a large literature and overcome the limitations of the two approaches proposed above. An attractive measure is that proposed by Foster, Greer, and Thorbecke (1984).

The Foster-Greer-Thorbecke (1984) index is:

$F G T=\frac{1}{n} \sum_{i=1}^{q}\left[\frac{z_{i}-y_{i}^{\pi}}{z_{i}}\right]$

where

$n=$ the total number of households in the population

$q=$ the number of poor households

$z_{\mathrm{i}}=$ the household poverty line

$y_{i}=$ household $i$ income

$\alpha=$ a "poverty aversion parameter" $\alpha \geq 0$

The FGT index is simply a count ratio if $\alpha=0$ or the product of the count ratio and a normalized poverty deficit if $\alpha=1$. However, for higher values of $\alpha$, raising each normalized deficit to the power means that poor households are weighted more heavily in the index calculation. For very large values of $\alpha$, the index becomes "Rawlsian" since all the weighting is placed on the poorest household.

Following the presentation of the instruments for measuring poverty, we plan to orient our work towards identifying the structural causes of poverty.

\section{Structural Causes Of Poverty}

Three major causes have been identified by economic literature namely access to financial market, influence of social capital, and finally the level of inequalities.

The issue of financial exclusion takes into account the access of a given category of the population to formal financial services. These financial services are of three types: savings, credit and insurance. It's formal credit that has received more attention in the literature and is discussed in its aspect of credit rationing. Many individuals or category of households are excluded from credit market and several factors could explain this exclusion. On the demand side, lack of awareness, low income / assets, social exclusion and illiteracy are barriers to accessing formal financial services. On the supply side, distance from bank branches, bank branch hours, cumbersome documentation and other procedures, unsuitable products, staff attitudes are common reasons mentinned. All these reasons mentionned above result in a higher transaction cost and lower profitability.

Regarding informal financial services and especially informal credit, the flexibility of conditions, ease of availability and other attractive features of this credit make it popular and explain its survival over time. Ouoya (2019b) shows that this informal credit, which is widely available in rural Côte d'Ivoire, holds the seeds for the sustainable maintenance of rural people into poverty. Many rural households, in order to benefit from these credits, do not hesitate to offer productive assets (cocoa plantations, agricultural land, etc.) as collateral. By this action, they lose the benefit of these goods for periods 
of up to three or four calendar years. Thus, even if these informal credits serve to meet the short-term needs of households, in the medium and long term they reduce these households' incomes and keep them into poverty. Access of poor to quality financial services is essential to promote inclusive economic growth and eradicate poverty. Limited access to the financial market acts as a significant barrier to improving the quality of life of poor and less advantaged populations (Mujeri 2015). Access to credit also plays a major role in the issue of child labor and its influence on the structural or long-term poverty status of the household.

Children influence households' welfare and the distribution of wealth particularly when the income is subject to risks not covered with borrowing constraints ... Hazarika and Sarangi (2008) show that poor households prefer sending children to work and thus avoid educating them. Such a choice could improve the current welfare of households by increasing their short term income but it guarantees the structural maintenance of these households in poverty. However, access to structural credit can alleviate this situation by allowing negative legacies. Parents with low initial endowments on the basis of their children's future income could transfer resources from the future to the present by borrowing. These parents will thus accomplish an inter-temporal transfer of resources by borrowing on the basis of their children's future earnings. Without access to credit, parents cannot make such transfers and will be forced to put their children to work rather than sending them to school. Improving access to credit reduces the working capital constraint of household's production and guarantees children's access to schooling (Hazarika and Sarangi, 2008). Like households' access to credit, the availability of social capital could be an asset in poverty reduction.

Social capital refers to the norms and networks that allow individuals to act collectively (Woolcock et al., 2000 cited by Togba, 2012). Intuitively, the basic idea of "social capital" is that family, friends, and various partners are important assets that can be called upon in a crisis. Fox (1996) defines social capital as social organization, a reciprocal cooperative relationship, networks and leadership facilitating collective action. At the community level, Jacobs (1961) presents it as a neighborhood network. People without social capital have a very limited set of information that can be useful in improving their living conditions. The network made up of parents, relatives, neighbors, religious communities, etc. is also a less expensive source of credit (Nandy, et al. 2016).

It is widely believed that access to productive assets, including land, human capital, livestock, and agricultural equipment can play an important role in improving the well-being of rural households. In particular, insufficient access to land and low productivity of land are considered to be major causes of rural poverty and food insecurity (Holden et al., 2008a). Like access to financial services, the persistent presence of inequalities can be a major factor in the aggravation of poverty among the population.

Barro (1999) classified the relationship between inequality and economic growth into four categories which are as follows: credit market imperfections; economic policy; social unrest and savings rates. Note that many households cannot have access to financial services and particularly formal credit. In addition to this, investment opportunities are closely related to the disposal of assets and substantial income. One of the implications of these facts is that the poor will not have access to investments with large returns. As a result, a redistribution of assets from the rich to the poor will enable the poor to access investment opportunities. They will thus be able to increase the rate of economic growth. Barro (1999) also argues that a higher degree of inequality would create economic distortions which in turn would reduce growth. Such a relationship would be explained by the fact that inequalities in wealth and income would motivate the poor to turn to crime and violence and thus hamper economic growth. Thus, reducing inequalities would have a positive effect on growth.

By formalizing the relationship between poverty, inequality and growth, Ravallion (1997) states that there are two channels through which inequality can affect poverty. The first channel is through the well-known relationship between inequality and growth and then between growth and poverty. High initial inequality retards growth, which in turn lowers the rate of poverty reduction. The second channel is the 'growth-elasticity' argument. The argument states that in a growth process where all income levels grow at roughly the same rate, higher inequalities mean that the poor earn less and that they will continue to have the lowest share of total income. Thus small increases in growth will lead to a lower rate of poverty reduction. However, it also means that the poor will suffer proportionately less from the impact of an event of economic contraction. However, it is useful to reiterate that inequality cannot be used as the only indicator of judgment of a country's economic performance. Inequality only measures the distribution of income or expenditure. In an extreme way, this means that in a country where everyone is poor, inequalities do not exist (Kaplow, 2002).

By this same argument, growing inequality does not necessarily have a negative implication. For example, increasing the income of individuals with high incomes without decreasing the income of others will increase inequality, but this is a much better situation than when no one experiences an increase in income (Feldstein, 1998).

Suryadarma et al., (2005) have shown the importance of reducing inequalities (by improving income distribution) as a means of increasing the impact of economic growth on poverty reduction because of the fact that inequality influences the elasticity of poverty growth. When the inequality increases, the elasticity decreases. At a high level of inequality, growth may have a lesser effect on the quest for poverty reduction.

The level of inequality raises the question of whether redistribution is necessary or not. There is controversy over the assessment of the effect of redistribution on growth. Easterly \& Rebello (1993) found that redistribution is detrimental to growth while Aghion et al. (1999) argue that the redistribution of wealth, of the rich whose marginal productivity of investments is relatively low because of a decreasing return on individual capital investments, to the poor whose marginal productivity of investments is relatively high for exactly the same reasons, would increase aggregate productivity and therefore growth. McCulloch et al. (2000) argue that inequality is an important aspect in poverty reduction and therefore it should be given more attention in poverty reduction efforts. 


\section{Examples Of Poverty Reduction Instrument: PRSPs}

Through this sub-section, we intend to make a brief presentation of Poverty Reduction Strategies Papers, their limits and then the alternative solutions proposed by the economic literature.

The PRSPs are a model for the practical application of poverty reduction policies across different countries. They emerged in 1999 as an attempt by the World Bank and the IMF to increase interest in the issue of poverty reduction and improve national ownership of the development process. In theory, the government of a given country writes the PRSP with consultation of stakeholders. In doing so, this government is highlighting the specific problems its country is facing and the specific solutions that best suit its people. Thus, PRSPs aimed to integrate diversity into the overall poverty reduction and development project. Despite this appropriation of these PRSPs by many nations, the limitations inherent in their design cannot be ignored.

A number of studies (e.g. Cheru 2006; Whitfield 2005), including those conducted by the IMF (2004) and the World Bank (2003) find that the reality of the Poverty Reduction Strategy (PRS) does not meet the ideals that motivated its creation. According to some studies, the various challenges that these studies have faced are specific manifestations of the problems inherent in a single and universal definition of poverty. First, PRSPs tend to design solutions to any local problem through the "common sense" application of "tried and true" methods. However "common sense" and solutions are generally developed outside the site where they are to be applied and are therefore developed without reference to local conditions.

Second PRSPs do not take into account the social context and the processes by which problems are identified and solutions defined. For the World Bank (2003) and IMF (2004), a recurring criticism of the PRS process is how stakeholder participation in the process has been reduced by power struggles between national governments and national bureaucracies. Such struggles have often excluded the elected representation of the countries concerned. Assuming that broad participation in the PRS process would be relatively unproblematic, this program did not adequately examine the ways through which the identification of national priorities are highly politicized and how this politicization would interfere within the poverty reduction process. Third, PRSPs tend to deal with poverty issues in a sectoral way, failing to address the trade-offs or mutual benefits that apply across different sectors (Carr, 2008). Thus, the PRSP 'approach has so far not contributed significantly to understanding the links between growth, the incidence of poverty and macroeconomic policies at the level of different countries (International Monetary Fund, 2004: 3).

For Carr (2008), we must get out of the definitional and operationalized trap created by a singular and universal "poverty". Rather, the diversity of situations labeled as 'poverties' should be viewed not only as different manifestations of the same problems in different places, but as different phenomena requiring a degree of individual attention. In other words, it is necessary to initiate this fight around "poverties" and not "poverty". This new generalization has two ramifications in terms of poverty reduction efforts. First, rather than focusing on sector performance indicators, a 'poverties' PRSP would address the different but locally linked aspects of social, economic and environmental processes based on an internal country analysis, contributing to different outcomes in terms of human well-being. Second, to focus on these processes, efforts to identify and measure poverty within these PRSPs will require different methods than those currently in use.

Addressing obstacles to human well-being through a critical and basic poverty approach leads us to a realistic and more sustainable path to poverty reduction. This helps to build poverty reduction programs from existing local management efforts, thereby enhancing the voices and strengths of the poor. Focusing on building the resilience of existing practices does not mean blindly valuing them. By addressing the challenges of human well-being through careful and systematic consideration of local social relations, we can develop a critical understanding of what works, and for whom, in a particular place. In this way, we manage to develop and increase responses that build resilience for all and not just one part. Such an approach is a much clearer plan for sustainable development than anything that has been offered (Carr, 2008).

In such a context of research for adequate poverty reduction strategies, risk analysis is increasingly used as risks can permanently modify the poverty status of an individual or a household. Thus, risk prevention has become a major concern of public policies: environmental risks, health risks, risks linked to economic shocks, which with globalization, have chain consequences linked to climate change. It is this taking into account of risks that has led researchers to no longer focus solely on ex post poverty analysis (static approach) but also to take into account a dynamic aspect in order this time to prevent poverty through analysis of vulnerability to poverty.

\section{CONCEPT OF VULNERABILITY TO POVERTY}

Research on vulnerability is closely linked to studies of risks and shocks they generate (Wisner et al. 1994 and 2003). They aim to identify the systems, elements of a system or groups of populations most exposed to the consequences of a severe disturbance. These approaches have led to the identification of "vulnerable systems" or "vulnerable populations" in order, in a prevention policy, to implement actions which make it possible to reduce the consequences of shocks on the elements thus targeted. This approach has been qualified as epidemiological management (Bidou et al., 2012). In the field of development studies, the emergence of economic vulnerability of populations dates back to the beginning of the 2000s. It followed in the wake of analyzes on poverty and joined the analysis of the consequences of natural disasters, political or other that plunge or keep part of the population in poverty.

Economics generally conceptualizes the vulnerability of populations as the result of an insufficient response to a risk. In the case of vulnerability to poverty this risk is that of becoming poor. This analysis is based on the concept of vulnerability, because it seems more appropriate to understand the situation of the population not by looking only at poor and non-poor households but also at those at risk of future poverty. This section will be presented in four subsections, namely first the definitions, causes and analysis approaches of vulnerability 
to poverty then, the instruments for measuring vulnerability to poverty, the classification of households according to poverty and vulnerability and finally household coverage and adaptation strategies.

\section{Definitions, Causes And Approaches To Analyzing Vulnerability To Poverty}

\section{Definitions}

To address the issue of defining vulnerability to poverty, note that different researchers from different disciplines generally use this concept of "vulnerability", but often with different meanings and measures. Alwang, Siegel and Jorgensen (2001), for example, define vulnerability as follows: A household is declared vulnerable following risky events if the future loss of well-being caused by these events exposes it to a level of well-being below socially accepted standards. The degree of vulnerability depends on the characteristics of these risks and the capacity of the household to respond to them. The ability to respond to risks depends on the characteristics of the household, including its asset base.

Moser's (1998) defines vulnerability as insecurity and sensitivity to the well-being of individuals, households and communities in the face of a changing environment. Moser (1998) identifies assets as the main means of resistance. Vulnerability is therefore closely linked to the ownership of assets. They create a buffer between production, exchange and consumption. Production activities and exchange create assets which when needed can be transformed into inputs of production or directly into a consumer good. Reduction in assets therefore increases vulnerability, although this may not be visible.

The observed poverty status of a household (defined simply by whether its observed level of consumption expenditure is above or below the preselected poverty line) is an ex-post assessment of household's living conditions, the $e x$ ante probability of this state can be understood as the level of household's vulnerability. Thus, within poverty eradication corpus, vulnerability is defined as ex-ante risk that a non-poor household will fall below the poverty line or that a poor household will remain poor (Chaudhuri et al., 2002). Cunningham and Maloney (2000) claim that vulnerability is defined in terms of exposure to adverse well-being shocks rather than in terms of exposure to poverty. Incomes variability resulting from fluctuations in harvests, input and output prices, and informal nature of non-agricultural jobs affect household's capacity to face risks. Thus, although average household income does not drop below poverty level, their degree of vulnerability can be high and this can cause problems linked to borrowing, repaying debts and managing risk. So vulnerability to poverty is defined as the risk that a household, poor or not, will remain or fall into poverty given risky events it faces or will face. Following this definition, we now want to identify the causes of household vulnerability to poverty.

\section{Causes Of Vulnerability To Poverty}

Two aspects should be mentioned at this stage, namely on the one hand exposure to shocks, on the other hand holding assets and household characteristics that can contribute to the attenuation of the effects of shocks. "Vulnerability to what?" can we read in "At risk" (Blaikie et al. 1994). For many risk management specialists, vulnerability is associated with a hazard specific to it: vulnerability to an earthquake is not the same as that associated with a flood or a locust invasion. It affects groups that may be different with varying intensity. The root causes of vulnerabilities are difficult to pinpoint. Whatever the disaster studied, we will find either very general elements such as bad governance, structures of economic domination and certain elements of social inequality, or stylized facts such as rapid growth of population, vicious circles of environmental degradation, etc. which are common to developing countries.

What makes households vulnerable to poverty? A household's vulnerability to poverty at any time depends on how its livelihood prospects and well-being will change over time. And that depends on its future income outlook, the degree of income volatility it faces, its ability to smooth consumption in face of income or other livelihood shocks. These in turn depend on the complex dynamic interrelationships between the environment - macroeconomic, institutional, socio-political and physical - in which theses households operate, the human, physical and financial resources it controls and its behavioral responses. Such a dynamic perspective on household wellbeing suggests that immediate causes of poverty and vulnerability to poverty are as follows:

- exposure to general adverse shocks (eg macroeconomic shocks or commodity price shocks) and / or unwanted idiosyncratic shocks.

- low capacity for long-run income generation.

On the one hand, transient vulnerability to poverty depends primarily on exposure to adverse shocks. On the other hand, structural or chronic poor are those who are both exposed to unwanted shocks and have limited long-run income generating capacity. Whether they are structural or transient poor, households can adopt a variety of coping strategies to meet their basic needs. Some of these coping strategies, although they may enable them to meet critical short-term needs, can be costly in terms of future well-being and, in particular, could doom the children to a life of poverty. Measures to prevent transmission of poverty from one generation to next must be an essential component of any sustainable strategy of poverty reduction.

An abundant literature (see Deaton (1992) and Browning \& Lusardi (1996) for excellent overviews) suggests that household consumption in any period will in general depend on a number of factors. These include the wealth of these households, their current income, expectations of future income (i.e. life prospects), uncertainty on which their future income is tied and their ability to smooth consumption when facing various income shocks. A household is more likely to be exposed to unwanted shocks and has limited earning prospects and income generation capacity if it has low levels of human capital and has a limited access to information; a such household suffers from physical and psychological disabilities ; has few productive and financial assets; suffers from social exclusion or inadequate social support networks; has limited access to credit and risk management instruments; lives in a setting with unfavorable agro-climatic conditions and limited natural resources ; lives in a community where entrepreneurial activity and job creation are insufficient; works in a sector 
particularly sensitive to macroeconomic volatility and sector shocks.

Following this non-exhaustive presentation of the causes of household vulnerability to poverty, we focus in the following part on approaches to analysiing vulnerability to poverty.

\section{Vulnerability Analysis Approaches}

The economic literature identifies four distinct approaches to analyzing household vulnerability to poverty. These are income or consumption approach, asset approach, livelihood approach and capability approach.

Works on poverty initially focused on an income and / or consumption approach. Methodologically, this approach remains the simplest for building indicators, thresholds and therefore standards such as the poverty line. Thus, populations are classified taking into account their position in relation to this line. After a descriptive and relatively static approach, the need arose to understand when and how households risk falling into poverty, with a view to prevention. Vulnerability to poverty analysis methods have been developed in numerous works, including Chaudhuri (2003), Ligon and Schechter (2003), Dutta et al. (2011) who propose an econometric approach based on households (or even individuals) data collected during surveys. These surveys should be carried out periodically and will be used to collect information on the income and consumption of the same individuals. Thus, income or consumption approach determines the status of vulnerability to poverty according to a threshold established from a minimum level of income or expected consumption acceptable in a given society. From this analysis, Chaudhuri (2003) distinguishes three groups of households namely the non-poor, the transitory poor and the chronically poor caracterized by the structural weakness of their income.

The advantage of asset-based approach is that it takes better account of the risks and the responses of individuals and households. Here, households in order to better respond to the risks they face, can build a portfolio of assets as a precaution or can adopt preventive measures. The asset-based approach states that households acquire and hold assets to guard against future shocks.

The analysis of vulnerability by means of subsistence (livelihoods) reflects a connection between economics and sociology (Chambers and Conway 1992, Ellis and Freeman 2005). This approach, having been adopted by development agencies such as the UK Department for Cooperation, is sparking new interest in research on rural societies. Vulnerability is conceived as a changing multidimensional state which makes it difficult to describe it by indicators. The livelihood or subsistence strategies are defined according to the access rights of groups to material and social resources allowing their conversion into activities. The institutional, legal and cultural framework is therefore decisive but the context of vulnerability plays an equally essential role. This context includes shocks (economic, health, natural), trends or changes in the context that can weaken populations (economic liberalization, technological change, political instability) and finally, very characteristic to rural areas, seasonal variations in production, prices or even job prospects. Using this method, the characterization of groups according to their livelihood strategies makes it possible to assess their vulnerability profile in relation to the hazards that may strike them. Here, poverty, risks and vulnerability are often associated phenomena and even sometimes confused in economic analysis.

The capability approach developed under the leadership of A. Sen emphasizes the multidimensional aspect of well-being, and the capacity of individuals "to be able to be" and to "be able to do" which conditions their aptitude to respond to the risks they must face (Dubois and Mahieu, 2009 cited by Bidou et al., 2012). However, the analysis of vulnerability to multidimensional poverty is still poorly developed (Calvo, 2008). The emphasis is on the consequences of a shock, a hazard or the materialization of a risk to the detriment of the analysis of the origin and the nature of these disturbances. This research orientation presents points of convergence with the livelihoods approach, developed in 1992 by Chambers and Conway and taken up in the form of numerous empirical studies by several development operators. After presenting these analysis approaches, we focus our work on measuring vulnerability to poverty.

\section{Vulnerability To Poverty Measurement}

Measuring vulnerability requires overcoming a number of prior methodological challenges. These challenges relate to the analytical framework, data, choice of the line of vulnerability and time horizon of the assessment.

\section{Methodological Challenges}

Vulnerability assessments differ from usual poverty assessments in two ways. First, vulnerability assessments are by definition forward looking while poverty assessments focus on information from the recent past. Second, vulnerability assessments must be rooted in explicit models of inter-temporal household behavior (Swain et al., 2008). An attractive definition of vulnerability to poverty is "the propensity to suffer a significant shock affecting well-being pushing household below the socially defined minimum level" (Alwang, Siegel, and Jorgensen 2001). This definition deserves clarification when considering measuring vulnerability. Three points require clarification:

First, what do we mean by "well-being shocks"? The measure of well-being most used by economists in this context is per capita consumption, although other measures such as income could be used. So a 'shock' to well-being is commonly measured as a change in per capita consumption. This shock could be negative or positive although we are concerned with shocks in the more traditional sense of a harmful event. Also by focusing on consumption and not on income or assets, we implicitly allow households' coping mechanisms to be at the forefront of households' strategy. The use of income as a measure of well-being overestimates households' well-being in times of plenty and underestimates it in years of drought; by using consumption as an indicator of well-being, we enable households to respond to this recurring phenomenon.

Second, what is the 'socially defined minimum level' of well-being appropriate? Here we are using the poverty line. Poverty studies generally use an absolute poverty line. Third, how should we measure the "propensity to suffer significant shock"? A good practical way to measure vulnerability is to take into account the probability of being 
poor in the following year (Chaudhuri et al. 2002) or at points beyond the next few years (Pritchett, Shryahadi, and Sumarto 2000). There is, however, a certain degree of arbitrariness in making these decisions. Following the presentation of general framework of this evaluation, we note that one of the major challenges of evaluating vulnerability to poverty is the availability of adequate data.

The existing literature aiming to estimate the aggregate vulnerability of households is based on the pioneering work of Townsend (1994) and Udry (1995), who were the first few to use panel data to analyze whether households were able to insure their consumption against idiosyncratic fluctuations in income over time and space. With this in mind, many studies have followed analyzing fluctuations in consumption over time (Dercon and Krishnan, 2000; Morduch, 2005) and concluding that households are partially but not fully able to insure their consumption against fluctuations in returned. A severe disadvantage of this literature is that it is based on panel data, very limited data at developing country level.

The other element relating to the empirical literature on vulnerability to poverty is its restrictive and limiting nature. Idiosyncratic and covariate shocks are very limited and sometimes absent in household surveys (Günther and Harttgen, 2009). Consequently, many authors have focused their work on the impact of selective shocks on consumption (Dercon and Krishnan, 2000).

The choice of the line separating those who are vulnerable to poverty and those who are not is arbitrary, but researchers typically use one or two thresholds.

- A 50 percent probability of being poor. In this case, a household has at least the same chance of being poor the following year. Such households are often referred to as "highly vulnerable".

- A probability of being poor equal to $P_{0}$ (where $P_{0}$ is the poverty rate). It can be shown that under plausible assumptions, the average vulnerability to poverty - which is the average probability of being poor - equals the poverty rate. Households whose probability of being poor is greater than $P_{0}$ but less than $50 \%$ are sometimes categorized as 'low vulnerability' '. It seems intuitive to say that a household is "vulnerable" if it faces a 50 percent or more chance of falling into poverty in the near future.

The other, no less important aspect of an operationally useful vulnerability index is deciding the time horizon from which the vulnerability of households should be assessed. The existing literature is of minor help on this point. In most cases, the time horizon is defined through some arbitrary expressions such as 'probability of falling into poverty in the near future', showing that there is no clear choice. Recognizing the need for a certain degree of arbitrariness, Chaudhuri (2003) proposed two possible cases - a one-year time horizon, which can be linked to the probability of short-term poverty, and a time horizon of three years which corresponds to the probability of poverty in the medium term.

With a vulnerability threshold of $V_{n}=0,5$ indicating the probability of falling into poverty at least once in a year, the probability of falling into poverty in subsequent years i.e. one, two or three years can be calculated using the following equation:

$V^{*}=1-\sqrt[n]{1-V_{n}}$

This table 1 below present the level of households' vulnerability at diferent time horizons.

Finally, if a household is right on the poverty line and is facing zero average shock, that household has a vulnerability score of 0.5 over one year time horizon. This implies that when the time horizon tends towards zero, being in the 'current period in poverty' and being 'vulnerable to poverty in the current period' coincide (Pritchett et al. 2000). Also, as the time horizon increases, the probability of remaining poor decreases as shown in this table below.

Table 1 Relationship between time horizon and vulnerability threshold

\begin{tabular}{cc}
\hline Time horizon & $\begin{array}{c}\text { Vulnerability threshold } \\
V_{\mathrm{n}}=0,5\end{array}$ \\
\hline One year & 0,5 \\
Two years & 0,292 \\
Three years & 0,206 \\
\hline
\end{tabular}

Source Our calculations based on the equation defined above 


\section{Assessment Tools}

Three major vulnerability assessment tools are available in the economic literature. The aim here is to give an overview of these different tools, to conduct a comparative analysis and finally make a more comprehensive presentation of the tool that has held the most attention of researchers in recent decades.

According to Hoddinott and Quisumbing (2003), there are three main approaches to assess vulnerability: vulnerability as expected poverty is the probability of falling into poverty in the near future (VEP) (Chaudhuri, 2003; Chaudhuri et al., 2002; Christaensen and Subbarao, 2001), vulnerability as low expected utility (VEU) (Ligon and Schechter, 2003) and vulnerability as uncovered exposure to risks (VER) (Tesliuc and Lindert, 2004). The VEU approach defines vulnerability by referring to the difference between the utility derived from a certain level of certain per capita consumption (similar to the poverty line above which the household could only be considered vulnerable) and the expected utility of consumption. All of these approaches are based on a model that predicts a measure of well-being as a function of household characteristics and household exposure to risk. The VEP and VEU approaches apply a benchmark for this measure of well-being and determine a probability that households will fall below this benchmark. The VER approach, however, does not construct such a probability, but assesses whether the observed shocks generate welfare losses. Thus, this approach is an ex post assessment of the extent to which a negative shock causes a household to deviate from expected well-being.

The approach of Ligon and Schechter (2003) is advantageous in that the vulnerability estimate reflects low asset levels, unfavorable parameters and inability to adapt to shocks (both idiosyncratic and covariant). On the other hand, this approach is criticized for several aspects; first, the specification of a particular functional form for the utility function affects the magnitude of the calculated vulnerability estimate. Second, since utility is the focal point of this approach, the unit of measurement will likely need to be the unit of utility, e.g. useful, which can be difficult for policy makers to understand (Hoddinott and Quisumbing 2003).

The VER approach unlike other approaches is oriented towards the past. It gives an ex-post measure of welfare losses rather than an ex-ante measure of those losses due to negative shocks. Moreover, unlike the other two approaches, it does not attempt to give an aggregate measure of vulnerability. According to Ligon and Schechter (2003), the measurement of vulnerability allows a quantification of the loss of well-being associated with poverty. This loss of well-being stems from both idiosyncratic and aggregate risks exposing households to consumption shocks.

At first glance, the task of measuring vulnerability seems daunting. In principle, we should have the following information about each household:

- What resources will they be able to obtain in the following year, including assets such as land as well as their educational capital and their skills and experience;
- What risk they face? - such as drought, high food prices, disease, etc.; the probability of each type of risk; and the effect of each group of risks on their resources;

- Their ability to cope with each group of risks - for example by feeding off the stock of maize, or mobilizing family support networks, or borrowing money or working harder.

It is clearly impossible to collect all of this information necessary for such an analysis, and it also appears impossible to model all possible behavioral responses for the household. The solution, as in any modeling, is to simplify the situation sufficiently to make the problem treatable. In the simplest cases, three types of information and one additional assumption are enough to allow us to measure household vulnerability to poverty. These categories of required information are as follows:

The level of households' expected per capita consumption in the following period given by $E\left(c_{t+1}\right)$

The variance of the level of this per capita expected consumption for the following period $\sigma^{2}$

\section{The poverty line $z$}

To this information, we add the hypothesis that the expected level of consumption follows a known distribution such as the normal (Gaussian) distribution. Formally, in the case of one period $c_{h, t}$ the per capita consumption of the household $h$ at time $t$ and $z$ the poverty line, a household is considered poor

if: $c_{h, t}<z$

Now, let's define household vulnerability. $c_{h_{i} t+1}$ being per capita expected consumption of the household $h$ at time $t+1$ et $v_{h_{x} t}$ the probability of the household $h$ falling into poverty at time $t+1$.

Vulnerability could be measured by the following equation: $v_{h_{t} t}=\operatorname{Pr}\left(c_{h_{t} t+1} \leq z\right)$

The vulnerability of a given household to poverty is here the probability that its expected per capita consumption is below the poverty line. This vulnerability may be due to low consumption or high variability in consumption. The practical problem encountered in this evaluation relates to the

fact that $c_{h_{s} t+1}$ is not directly observable, because it represents the expectation of per capita consumption of the household in the following period. The model presented by Chauhuri et al. (2002) gives a functional form from which this expected consumption can be assessed. Thus, from this assessment, we can classify households as follow.

\section{Households' Classification}

This classification of households will be based on two criteria, one being the vulnerability to poverty status, and the other being the vulnerability status combined with expected and current consumption.

According to first criteria, Chaudhuri et al. (2002) reveal three categories of households:

The " highly vulnerable", for whom $\hat{v}_{h}>0.5$;

The "relatively vulnerable" for whom 
$P_{0}<\hat{v}_{h}<0.5$ where $P_{0}$ is the poverty rate ;

Those who are not vulnerable $\hat{v}_{h}<P_{0}$.

Chaudhuri (2002) shows that more than half of the vulnerable population is not currently poor. Numerous works including that of Ouoya (2019) have also shown that in a given sample of households, the population vulnerable to poverty is always greater than those who are poor. This is why it is not enough to use the current poverty status as a proxy for whether someone will be poor in the next period.

According to the second classification criteria, households can be grouped into several categories taking into account poverty and vulnerability status as presented in the table 2 below.

$\underline{c}$ is the consumption of the poverty line, ${ }^{v}$ the probability for a given household falling into poverty. From this above table, households can be classified as follow :

Poor $=\mathrm{A}+\mathrm{B}+\mathrm{C}$

- $\quad$ Chronic Poor $=\mathrm{A}$

- Transient Poor $=\mathrm{B}+\mathrm{C}$

Non-poor $=\mathrm{D}+\mathrm{E}+\mathrm{F}$

- High Vulnerability Non-poor $=\mathrm{D}+\mathrm{E}$

- Low Vulnerability Non-poor $=F$

High vulnerability Group $=\mathrm{A}+\mathrm{B}+\mathrm{D}+\mathrm{E}$

- Low Level of Espected Consumption $=\mathrm{A}+\mathrm{D}$

- High variability of Consumption $=\mathrm{B}+\mathrm{E}$

Low Vulnerability Group $=\mathrm{C}+\mathrm{F}$

Total Vulnerable Group $=\mathrm{A}+\mathrm{B}+\mathrm{D}+\mathrm{E}$

This categorization of household according to their poverty and vulnerability to poverty status is based on Suryahadi and Sumarto (2003).

This categorization process above could thus result in overlapping household groups. First, the population is divided into two distinct groups using the consumption threshold of the poverty line: the "poor" and the "non-poor". Those with an average consumption at or below the poverty line are generally identified as 'poor' and the others 'non-poor'. The poor are broken down into two distinct groups: the "chronic poor" and the "transient poor". The chronically poor are those who are currently poor and also have their expected level of consumption below the poverty line. These households are more likely to remain poor in the future. The transient poor on the other hand are those who are currently poor but their expected consumption is above the poverty line. Some of these transient poor have low vulnerability but others of them have high vulnerability. As a result of this process, a total of five groups emerge: the 'poor', the 'non-poor', the 'high vulnerability group', the 'low vulnerability group' and the 'total vulnerable group'.

The non-poor can be partitioned into two separate groups - the 'vulnerable'non-poor' and the non vulnerable nonpoor' based on their degree of vulnerability, their expected level of consumption and their initial poverty status.

The constituents of the "total vulnerable group" are the households associated with the high vulnerability group and those which are currently poor. This kind of categorization is important both theoretically and practically. It is emphasized that the poor and the vulnerable are not the same - they are distinct groups although they are not mutually exclusive. The total vulnerable group thus includes the poor in the current period plus all those who are not poor in the current period but who have a relatively high chance of falling into poverty in a near future.

For the chronically poor who lack economic assets, priority could be given to reducing fluctuations in consumption and building up assets through a combination of protective and promotional programs. Access to financial services, for example, through micro-programs, could help poor households to build up assets as this helps stabilize income and consumption, enable the acquisition of inputs and productive assets and protect against crisis.

At the end of this categorization, in the following section, we should provide an overview of the nature of the shocks that generate the status of vulnerability to poverty and then present the different strategies developed by households to improve their vulnerability status.

Table 2 Household classification table according to consumption and vulnerability to poverty

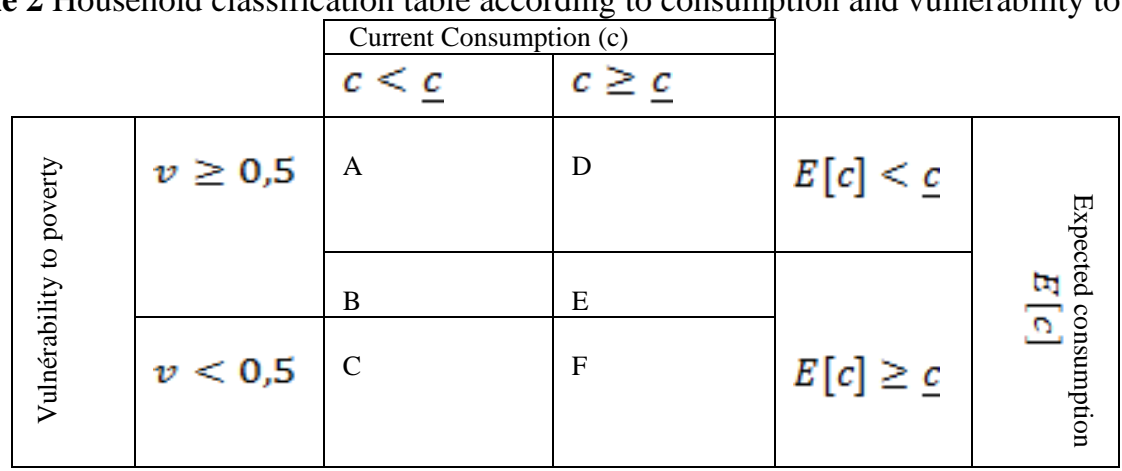

Source Suryahadi, A. and S. Sumarto (2003). Poverty and vulnerability in Indonesia before and after the economic crises. Asian Economic Journal, 17(1): 45-64. 


\section{Households' hedging and coping strategies}

Households face various risks. When these risks materialize, they generate shocks at the household level. Some shocks affect the whole community and are identified as covariate. Financial and economic crisis, natural disasters, etc. are identified in this group. Other shocks affect one or a few households and are identified as idiosyncratic shocks. This is the case for example with the death of a family member or the loss of a job. Analysising the type of vulnerability identified is crucial in determining the type of program to set up, the ideal time for its introduction or level adjustments to be made and the extent of the measures to realize. To make these decisions, policy makers need to have access not only to macroeconomic indicators but also to indicators that allow an understanding of the level of household vulnerability and risk profiles, risk management mechanisms particularly in the direction of poor. Note that there is a significant difference between coping strategies and household coverage strategies. Hedging or prevention strategies refer to risk. This involves setting up mechanisms that can prevent the occurrence of the shock associated with a given risk or installing a system to help cope with the consequences of the shock in the event of the latter occurring. Coping strategies are useful when the shock has already occurred. They include all the mechanisms that should allow the household to adapt to the consequences of the shock. Hedging strategies are ex ante to shocks while coping strategies are ex post. Based on this presentation, it would be imperative to provide an overview of these different strategies according to the economic literature. It will be a question here of presenting the risk management mechanisms of the World Bank then coping strategies developed by households and those developed by other actors.

Policies aimed at reducing vulnerability to poverty need to be oriented in two directions: first they must raise the average level of well-being like any anti-poverty program; Second they must focus on reducing risks and their consequences essentially through insurance mechanisms. This is the starting point for the renewed interest in social risk

Table 3 Risk management mechanisms

\begin{tabular}{|c|c|c|c|c|}
\hline & \multicolumn{2}{|l|}{ Informal mechanisms } & \multicolumn{2}{|c|}{ Formal mechanisms } \\
\hline & Individual and household level & Group-based & Market-based & Provided by public sector \\
\hline Reducing risk & $\begin{array}{l}\text { - practices preventive health } \\
\text { - migration } \\
\text { - more secure income sources }\end{array}$ & $\begin{array}{l}\text { - Collective action for } \\
\text { infrastructure, } \\
\text { dikes, terraces } \\
\text { - Management of } \\
\text { common property } \\
\text { resources }\end{array}$ & & $\begin{array}{l}\text { - sound macroeconomic policies } \\
\text { - environmental policy } \\
\text { - education and training policy } \\
\text { - public health policy } \\
\text { - Infrastructure } \\
\text { - labor market policies }\end{array}$ \\
\hline Mitigating risk & - crops and plots & - professional & - savings accounts in & - agricultural extension \\
\hline Diversification & $\begin{array}{l}\text { - Income source } \\
\text { - physical investment } \\
\text { and human capital }\end{array}$ & $\begin{array}{l}\text { associations } \\
\text { - associations of } \\
\text { revolving credit }\end{array}$ & $\begin{array}{l}\text { Financial institutions } \\
\text { - microfinance }\end{array}$ & $\begin{array}{l}\text { - liberalized trade } \\
\text { - protection of property rights }\end{array}$ \\
\hline Insurance & $\begin{array}{l}\text { - marriage and extended family } \\
\text { - sharecropping (rental of } \\
\text { agricultural plot against } \\
\text { production share) } \\
\text { - buffer stocks }\end{array}$ & $\begin{array}{l}\text { - investment in } \\
\text { social capital }\end{array}$ & $\begin{array}{l}\text { - retirement pensions } \\
\text { - accident, disability } \\
\text { and other Insurance }\end{array}$ & $\begin{array}{l}\text { - pension systems } \\
\text { - compulsory insurance for } \\
\text { unemployment, sickness, } \\
\text { invalidity }\end{array}$ \\
\hline $\begin{array}{l}\text { Coping with } \\
\text { shocks }\end{array}$ & $\begin{array}{l}\text { - sale of assets } \\
\text { - lender loan } \\
\text { - child labor } \\
\text { - reduction in food consumptior } \\
\text { - seasonal / temporary } \\
\text { migration }\end{array}$ & $\begin{array}{l}\text { - transfers from mutual } \\
\text { support networks }\end{array}$ & $\begin{array}{l}\text { - sale of financial assets } \\
\text { - loans from financial } \\
\text { institutions }\end{array}$ & $\begin{array}{l}\text { - Social assistance } \\
\text { - workfare } \\
\text { - subsidies } \\
\text { - social funds } \\
\text { - cash transfers }\end{array}$ \\
\hline
\end{tabular}

Source : World Bank 2000, 141 (lightly modified)

management, an approach aimed at social protection. The World Bank encourages the use of Risk and Vulnerability Assessments RVAs which is a 'diagnostic tool' designed to:

- Understand the sources of vulnerability to poverty (What are the most frequent and severe shocks? Which groups are at the highest risk of falling into poverty because of the consequences of these shocks?)

- Establish the catalog of public intervention measures aimed at managing social risks.
Focusing on Risk and Vulnerability Assessment (RVAs) refers to the widespread belief that the poor are the only ones who are most prone to shocks and they have few mechanisms to cope with such shocks (probable). This makes them understandably risk averse and as a result they may be less predisposed to innovate; this fact can also force them to withdraw their children prematurely from school. The table 3 above presents the risk reduction and mitigation mechanisms then the coping strategies. 
This table takes into account three major areas of intervention, namely risk reduction, risk mitigation and coping with shocks.

In developing countries, households face substantial risks which they bear through risk management and coping strategies. These strategies take into account self-insurance through savings and informal insurance mechanisms. Ex post coping strategies can be subdivided into four main categories: i) asset-based strategies; (ii) assistance-based strategies; (iii) strategies based on borrowing; and (iv) behavior-based strategies. According to Haq (2012), the level of vulnerability and poverty is higher for households that adopt behavior-based strategies such as consuming less, increasing the labor supply and taking children out of school to put them to work. This type of strategy is practiced more often for natural / agricultural shocks than for economic shocks. These conclusions were also supported by Beegle et al. (2006) who found that in Tanzania, in response to transient income shocks, households adopt weakly as hedging strategies the increase in the supply of child labor and the extension of child labor when households have access to credit. Jacoby and Skoufas (1997) also showed that in India, unanticipated income shocks have a significant effect on the attendance of children to school and this attendance to school appears to play an important role in the strategy of auto insurance for poor households. It is often noted that households adopt more than one strategy to smooth their consumption. Households that adopt more than one coping strategy are relatively more vulnerable and poor. Ouoya (2020a) shows that only households facing health shocks adopt active coping strategies. However, only reducing food consumption, borrowing and selling assets are active strategies that have a positive impact on household's welfare.

Many other actors play a crucial role in supporting households in their fight to improve their living conditions in a shock situation. These actors are among others governments, institutions that aimed to fight against poverty, various financial institutions, etc. The major axes of their interventions are among others social protection, improving productivity enhancing activities, macroeconomic policy and access to credit.

Social protection is defined as all interventions by public organizations, private organizations, volunteers and social networks to support communities, households and individuals in their efforts aimed at preventing, managing and overcoming a defined group of risks and factors to which they are vulnerable. Social protection can be seen as a main component of growth and development strategies contributing to the development and growth of good through (i) the assurance of a stable and basic level of consumption to households and investment in human development which alone can secure the improvement of well-being over time; (ii) the support for correcting market failures that contribute to poverty for example the limited nature of insurance mechanisms available to the less fortunate; (iii) the facilitation of investments in physical and human assets reducing the risk of future poverty such as education subsidies; (iv) actions countering undesirable behavioral reactions to vulnerability such as postponing health care or switching to poor quality food which are understandable in the context of the situation of vulnerable households but limit growth and medium and long term development; (v) reducing incentives for counterproductive and anti-social behavior and adopting behavior that strengthens social cohesion and facilitates positive economic and social change. Social protection therefore has an important role to play in supporting economic and social development.

Productivity enhancing activities are defined as activities that can contribute to higher future income. These include, for example education, starting a new business or making investments in agricultural equipment or inputs. It is stated that better access to financial services can enable households to achieve higher levels of investment (as opposed to household consumption) which could directly contribute to income growth. According to the growth theory (Solow (1956) and Romer (1990)) growth depends on the stock of physical and human capital available in the economy as well as on technological progress. Investment at both the firm and individual level can contribute to all of these things and thus plays an important role in facilitating long-term growth.

Macroeconomic policies could help reduce vulnerability. Indeed there is a significant gain from the effective coordination of macroeconomic policy and social protection. Successful macroeconomic policies lead to stable economic growth and fiscal health is important to reducing vulnerability. These factors reduce the demand pressure on social protection and make the resources needed for social protection available. This was recognized by the Government of Grenada Medium Term Economic Strategy Paper 20032005 which noted that the " greater role of government is to promote growth and economic support in a context of macroeconomic stability and poverty reduction " (Government of Grenada 2003). Vulnerability is understood here as the extent to which shocks have undesirable effects on household consumption taking into account the assets, aids and strategies set up by households to mitigate their effects. Vulnerability is therefore the net effect of shocks after taking into account the resilience of households which is their ability to reduce or mitigate the adverse effects of these shocks (Barrientos, 2010). We define the term access to financial services as the ease with which individuals can use financial services if they want to.

Access to financial services is distinguished from it use: an individual can have access to financial services but choose not to use them. Access to credit enables households to borrow funds and can strengthen their productive assets. This is done through the fact that it enables households to invest in microenterprises, in new technologies that can improve productivity such as new and better tools, equipment, fertilizers, or in education and health and thus facilitate greater capital accumulation and growth (Ghosh, Mookherjee \& Ray(1999)). Eswaran and Kotwal (1990) argue that having access to credit could reduce the vulnerability of households to negative shocks by increasing their ability to smooth consumption during difficult times. Thus this availability of credit allows households to undertake risky investments as it enables them to better understand the consequences of poorly productive investments. Ghosh, Mookherjee \& Ray(1999) argue that credit is essential in allowing capital investments within the class of producers (farmers) who are not able to save and useful in giving to households the ability to obtain money 
in emergency situations. The availability of credit contributes to increase production and income.

Galor \& Zeira (1993) find that access to household credit can have a positive influence on growth through its impacts on the accumulation of human capital and this is affected by the initial distribution of wealth; richer families are more able to invest in the accumulation of human capital leading to improved growth. De Gregorio (1996) also argues that access to credit promotes the accumulation of human capital as credit constraints force students to work to support themselves and this reduces the time available for study. However, Ouoya (2019b) finds that credit quality plays a crucial role in its ability to reduce household vulnerability if not it produces the opposite effect. In Côte d'Ivoire, the author shows that informal credit widely available in rural areas could prove to be a trap that can lock the poor into a cycle of indebtedness and reduce their future incomes in the long term even if it improves the well-being of these households in the short term.

\section{CONCLUSION}

The conceptual challenge inherent in the analysis of poverty stems from the tendency of actors and researchers to attribute to it a universalizing and absolute nature. For Carr (2008), work should be directed towards a study of "poverties" instead of poverty. Each context giving rise to a situation of poverty is specific and deserve an analysis based on its particularities. Through such an analysis researchers should base theirs works on sectoral approaches to create a synergy allowing to face the basic question. Carr thus traces an intermediate path between the absolutes of the universalizing approaches to atomize the basic approaches in order to understand the "poverties".

We noted that instruments for measuring poverty are based on so-called subjective aspects on the one hand and objective on the other. Subjective measures derive their essence from the work of Townsend (1979). From a subjective point of view three approaches to measuring poverty can be identified namely the relative deprivation approach, the consensus approach and the capability approach. The first cited approach is part of the gradual shift from a physiological model of poverty based on the non-satisfaction of essential physical and material needs to a sociological model taking into account the social needs of individuals, such as those relating to participation in society (Shaffer, 2007). The "consensual" approach is based on a consensual vision of the definition of the necessities of life. According to the pioneering works of Nobel Prize winner Amartya Sen (see Sen, 1980, 1984, 1985), the central argument behind the capability approach is that the standard economic approach to well-being - based on utility or access to resources - excludes much relevant information and provides unreliable guides to poverty and well-being. The solution to this problem is to understand poverty and wellbeing in terms of human capacities or opportunities to achieve positive freedoms such as being able to live long, be well nourished, be literate, take part to community life and achieve self-esteem. From an objective point of view, it was Sen (1976) who produced a satisfactory measure of poverty. This measure manages to overcome all the limitations of the measures proposed in the previous literature. An attractive objective measure is that proposed by Foster, Greer, and Thorbecke (1984).

The concept of vulnerability extends the idea of poverty to include idiosyncratic and global risks. This vulnerability can be defined as the probability of being poor or falling into poverty in the future. It can be categorized on the micro and macro levels where macro vulnerability refers to global threats to social welfare for example globalization and recent international financial crises. Conversely, microvulnerability refers to household risks including health risks, economic shocks, social shocks, natural disasters and demographic shocks (Tesliucand Lindert, 2004). Vulnerability to poverty is strongly linked to the presence of risks (idiosyncratic or covariate) in the daily lives of households and above all to their behavioral responses to the shocks that these risks could generate. Although they are different, these concepts of poverty and vulnerability to poverty are closely related because of certain established facts: (i) the poor are typically more exposed to various risks and (ii) the poor have very few assets to face these risks and the shocks they could generate. Also, the importance of vulnerability is related to the fact that if policy makers design present-time poverty reduction policies taking into account the poverty line based on income and consumption in previous years, the poor who receive support from their income may have already lifted themselves out of poverty and the non-poor who do not receive such support may have slipped into poverty due to their failure to anticipate various shocks. Consequently, assessing vulnerability helps distinguish ex ante poverty prevention interventions from ex post poverty reduction strategies (Holzmann and Jorgensen, 2000).

Studies on vulnerability typically find that the proportion of individuals who are vulnerable to poverty substantially exceeds the proportion of the poor (Chaudhuri et al. 2002; Ouoya 2019b, etc.). An implication of this fact is that, for the purposes of implementing a poverty reduction policy, it becomes difficult to target between the poor and the non-poor. Information on those who are poor today is a good indicator of those who will be poor the next year only if people are persistently poor. Unfortunately, from one year to another many people change their poverty status. An ex post measure of poverty has its merits: for example, using current data, one could measure the effects of public intervention measures on the extent of poverty. However, policymakers are more interested in the effects their measures will have in the future. The solution would be to identify those who are vulnerable to poverty that is those who have a significant probability of being poor the following year (Haughton and Khandker, 2009). Chaudhuri et al. (2002) note that "to think about future measures of appropriate anti-poverty interventions (... which aim to prevent or reduce poverty...), the crucial need is then... an assessment of the vulnerability of households to poverty. "

At the end of this review it should be said that the design and implementation of sustainable and effective poverty reduction strategies must be based on taking into account two main aspects: the first will be to identify those who are currently poor to assess the effect of past policies on poverty; The second aspect will be the measurement of vulnerability to poverty. This last measure will be useful for taking into account risk phenomena in the daily life of households. It will 
thus be useful in implementing actions of future policies to combat poverty in a sustainable way. In addition, an appropriate review of risk coverage and shock mitigation

References

[1] Aghion et al., (1999). Competition, Imitation and Growth with Step-by-Step Innovation. The Review of Economic Studies, Vol. 68, No.3, pp. 467-492

[2] Alwang, J., Siegel, P. and Jorgensen, S. (2001). Vulnerability: A View from Different Disciplines. Social Protection Discussion Paper No. 0115, Social Protection Unit, Human Development Network, World Bank, Washington, DC.

[3] Azam, S. and K. S. Imai (2009). Vulnerability and poverty in Bangladesh. Chronic Poverty Research Centre Working Paper No.141.

[4] Barrientos, A. (2010). Vulnerability and Social Protection in Small Island States: The Case of Grenada. Social and Economic Studies, Vol. 59, No. 1/2

[5] Barro, R. (1999). Inequality, Growth, and Investment. NBER Working Paper No. 7038. National Bureau of Economic Research, Cambridge, MA, 1999.

[6] Beegle K., Dehejia R. and Gatti R. (2006) Child labor and agricultura shocks. Journal of Development Economics vol. 81 pp 80-96

[7] Bidou J.E. et Droy I. (2012). Peut-on mesurer la vulnérabilité sociale et économique des ménages et des individus. 21p. Colloque International GEMDEV UNESCO : La Mesure du Développement: Atelier 6 : Vulnérabilité et Pauvreté, Paris (FRA), 2012/02/01-03

[8] Blaikie. P., Cannon, T., Davis, I., and Wisner, B. (1994). At risk: Natural hazards, people's vulnerability, and disasters. Routledge: London.

[9] Browning, M., and A. Lusardi (1996). Household Saving: Micro Theories and Micro Facts. Journal of Economic Literature, 34, 1797-1855.

[10] Calvo, C. (2008). Vulnerability to Multidimensional Poverty. Peru: 1998-2002. World Development, 36(6) p. 1011-1020.

[11] Carr, E.R. (2008). Rethinking Poverty Alleviation: A 'Poverties' Approach. Development in Practice, Vol. 18, No. 6 pp 726-734

[12] Cerioli, A and Zani, S. (1990). A Fuzzy Approach to the Measurement of Poverty, in C.Dagum and M. Zenga (Eds) Income and Wealth Distribution, Inequality and Poverty. Heidelberg, Springer-Verlag.

[13] Citro, C. F. \& Michael, R. T. (1995). Measuring Poverty: A New Approach. Washington, DC: National Academy Press.

[14] Chambers R. et ConwayG., 1992, Sustainable Rural Livelihoods: Practical Concepts for the 21st Century. IDS Discussion Paper 296.

[15] Chambers, R., Longhurst, R., and Pacey, A. (1981). Seasonal Dimensions to Poverty. London, Frances Pinter.

[16] Chaudhuri, S. (2003). Assessing vulnerability to poverty: concepts, empirical methods and illustrative examples. Department of Economics Columbia University. Available at: instruments could enable the poor to escape from poverty in a sustainable manner.

http://info.worldbank.org/etools/docs/library/97185/Keny_03 04/Ke 0304/vulnerability-assessment.pdf

[17] Chaudhuri, S., Jalan, J. and Suryahadi, A. (2002). Assessing household vulnerability to poverty from crosssectional data: A methodology and estimates from Indonesia. Department of Economics Columbia University. Available at: http://digitalcommons.libraries.columbia.edu/econ dp/117.

[18] Cheru, F. (2006). Building and supporting PRSPs in Africa: What has worked well so far? What needs changing? Third World Quaterly, Vol. 27, No. 2 pp 355376

[19] Christiaensen, L. and Subbarao, K. (2001). Towards and Understanding of Vulnerability in Rural Kenya. Mimeo.

[20] Cunningham, Wendy V., and William F. Maloney (2000). Measuring Vulnerability: Who Suffered in the 1995 Mexican Crisis? World Bank, Washington, DC. Processed.

[21] De Gregorio J. (1996). Borrowing Constraints, Human Capital Accumulation, and Growth. Journal of Monetary Economics Vol. 37, pp 49-71.

[22] De Soto, H. (2000). The Mystery of Capital: Why Capitalism Triumphs in the West and Fails Everywhere Else, New York, NY: Basic Books.

[23] Deaton, A. (1992). Understanding Consumption. Oxford, Oxford University Press.

[24] Dercon, S., and Krishnan, P. (2000a). In Sickness and in Health: Risk-Sharing within Households in Ethiopia. Journal of Political Economy vol. 108(4) pp 688-727.

[25] Dubois J-L., Mahieu R. (2009). Glossaire « Les mots de Sen et au-delà ». Sen, libertés et pratiques de développement. Revue Tiers Monde, vol. 198 pp 373-381

[26] Dutta I., Foster J. and Mishra A. (2011). On measuring vulnerability to poverty. Social Choice and Welfare, Vol. 37, No. 4, Special issue in honor of Prasanta K.

[27] Ellis, F. and Freeman, A. (2005). Rural livelihoods and poverty reduction policies. Routledge, - $408 \mathrm{p}$.

[28] Eswaran, M. and Kotwal, A. (1990). Implications of Credit Constraints for Risk Behaviours in Less Developed Economies. Oxford Economic Papers, N-S., 42(2): 473482

[29] Easterly, W. and Rebello, S. (1993). Fiscal Policy and Economic Growth: An Empirical Investigation. Journal of Monetary Economics, vol. 32(3), pp. 417-458.

[30] Feldstein, M. S. (1998). Income Inequality and Poverty. NBER Working Paper No. W6770.

[31] Foster, J. E., Greer, J. and E. Thorbecke. (1984). A Class of Decomposable Poverty Measures. Econometrica, 52(3): $761-766$.

[32] Fox, J. (1996), "How Does Civil Society Thicken? The Political Construction of Social Capital in Rural Mexico", World Development 24(6):119-149 
[33] Galor, Oded, and Joseph Zeira. 1993. "Income Distribution and Macroeconomics." Review of Economic Studies 60(1) : 35-52

[34] Ghosh, P., Mookherjee, D. and Ray, D. (1999). Credit Rationing in Developing Countries: An Overview of the Theory. Dilip Mookherjee and Debraj Ray (eds),A Reader in Development Economics, London: Blackwell (2000)

[35] Government of Grenada. Ministry of Finance. (2003). Medium term economic strategy paper 2003-2005. MTESP.

[36]

Günther, I. \& Harttgen, K. (2009). Estimating Vulnerability to Idiosyncratic and Covariate Shocks. World Development. 37(7), pp 1222-1234

[37] Haq, R (2012). Shocks as a Source of Vulnerability: An Empirical Investigation from Pakistan. Poverty and Social Dynamics Paper Series PSDPS : 6. Pakistan Institute of Development Economics.

[38] Hazarika, G. and Sarangi, S. (2008). Household Access to Microcredit and Child Work in Rural Malawi. World Development, Vol. 36, No. 5, pp. 843-859

[39] Hoddinott, J. and Quisumbing, A. R. (2003). Data Sources for Microeconometric Risk and Vulnerability Assessments. Manuscript, International Food Policy Research Institute, Washington DC.

[40] Holden, S. T., Otsuka, K., \& Place, F. M. (2008a).The emergence of land markets in Africa: impacts on poverty, equity, and efficiency. Washington DC: Resource For the Future (RFF) publisher.

[41] International Monetary Fund (IMF). 2004. Côte d'Ivoire: Statisticaly Appendix. Washington, D.C.: International Monetary Fund.

[42] Jacobs, J. (1961), The Death and Life of Great American Cities. New York: Vintage

[43] Jacoby, H. G., and Skoufias. E. (1997). Risk, Financial Markets, and Human Capital in a Developing Country. Review of Economic Studies, 64 (3):311-35.

[44] Kaplow, L. (2002). Why Measure Inequality? NBER Working Paper No. 9342. National Bureau of Economic Research, Cambridge, MA.

[45] Ligon, E. and Schechter, L. (2003). Evaluating Different Approaches to Estimating Vulnerability. Social Protection Discussion Paper Series, No.0410. Social Protection Unit, Human Development Network, The World Bank, Washington D.C.

[46] Mack, J. \& Lansley, S. (1985). Poor Britain. London, Allen and Unwin

[47] McCulloch, N., B. Baulch, M. Cherel-Robson. (2000). Poverty, Inequality, and Growth in Zambia during the 1990s. Paper prepared for the 26th General Conference of The International Association for Research in Income and Wealth, Cracow.

[48] Morduch J. (2005). Consumption smoothing across space: Testing theories of risk-sharing in the ICRISAT study region of South India. In Insurance against Poverty. ed. S. Dercon, Oxford University Press, Oxford.

[49] Moser, C. 1998. The asset vulnerability framework: Reassessing urban poverty reduction strategies. World Development, vol. 26 (1), pp 1-19
[50] Mujeri M.K. (2015). Improving access of the poor to financial services. A Report prepared for the General Economics Division of the Planning Commission to serve as a background study for preparing the 7th Five Year Plan (2016-2020) of Bangladesh.

[51] Nandy, S., Pomati, M. and Lenoel, A. (2016). Approche Consensuelle de Mesure de la Pauvreté : une Application au Cas du Bénin. Stateco, 110

[52] Nussbaum, M. (1999). Sex and Social Justice. New York, Oxford University Press.

\section{G}

[53] Ouoya, Z.M. (2020a). Coping Decision, Strategies And Rural Households Welfare In Cote D'ivoire. Studies and Scientific Researches. Economics Edition, Vol 31, pp 5569 , available http://sceco.ub.ro/index.php/SCECO/article/view/446, DOI : http://dx.doi.org/10.29358/sceco.v0i31.446

[54] Ouoya, Z. M. (2019b). Business Sector, Level of Education and Access to Credit: What Influences on Vulnerability to Rural Households Poverty in Côte d'Ivoire? Studies and Scientific Researches. Economics Edition, Vol 30, pp 45-64 available at http://sceco.ub.ro/index.php/SCECO/article/view/441/pdf

[55] Pritchett, L., A. Suryahadi and S. Sumarto (2000). Quantifying Vulnerability to Poverty: A Proposed measure Applied to Indonesia. Policy Research Working Paper no. 2437. Washington DC: The World Bank

[56] Rahman, H. Z. and Hossain, M. (1995). Rethinking Rural Poverty: Bangladesh as a Case Study, Dhaka, University Press Limited

[57] Ravallion M (1998) Poverty Lines in Theory and Practice. Living Standards Measurement Study Working Paper No. 133. Washington, DC: World Bank.

[58] Ravallion, M. (1997). Can high inequality developing countries escape absolute poverty? Economics Letters, vol. 56, pp 51-57

[59] Romer, P.M. (1990). Endogenous Technological Change. Journal of Political Economy, 98, pp S71-S102.

[60] Rowntree, S. (1901) Poverty. The Study of Town Life. London : Macmillan. http://www.jrf.org.uk/centenary/poverty.html

[61] Ruggeri Laderchi C., Saith R. and Stewart F. (2003). Does it Matter that we do not Agree on the Definition of Poverty? A Comparison of Four Approaches. Oxford Development Studies, Vol. 31, No. 3.

[62] Schultz, T.W., (1980). Nobel lecture: The economics of being poor. Journal of Political Economy. 88 (4) pp 639651.

[63] Sen, A. (1992). Inequality Reexamined. Cambridge, Mass: Harvard University Press.

[64] Sen, A.K. (1985a). Women, technology and sexual divisions. Trade and Development, vol. 6, pp 195-223.

[65] Sen, A. K. 1984. Resources, Values and Development. Oxford, Basil Blackwell.

[66] Sen, A. K. 1980. Equality of What? pp. 195-220 in McMurrin, S. M. (ed.), The Tanner Lectures on Human Value. Salt Lake City, University pf Utah Press.

[67] Sen, A. (1981). Poverty and famines. Oxford: Oxford University Press. 
[68] Sen, A. K. (1976). Poverty: An Ordinal Approach to Measurement. Econometrica 44(2):219-31.

[69] Shaffer, P. (2007). New Thinking on Poverty: Implications for Globalisation and Poverty Reduction Strategies. DESA Working Paper series, New York: United Nations Department for Economic and Social Affairs.

[70] Solow R.M. (1956). A Contribution to the Theory of Economic Growth. Quarterly Journal of Economics, 70, pp.65-94.

[71] Stewart, F. (2000). "Income Distribution And Development, " QEH Working Paper Series - QEHWPS37 prepared for a High Level Panel of Experts for UNCTAD X, Bangkok, February 2000.

[72] Suryadarma, D., Artha R.P., Suryahadi, S. (2005). A Reassessment of Inequality and its Role in Poverty Reduction in Indonesia. SMERU Working Paper.

[73] Suryahadi, A. and S. Sumarto (2003). Poverty and vulnerability in Indonesia before and after the economic crises. Asian Economic Journal, 17(1): 45-64.

[74] Swain, R.S., and Floro, M. (2008). Effect of Microfinance on Vulnerability, Poverty and Risk in Low Income Households. American University, Department of Economics, Working Paper series.

[75] Togba, E.L. (2012). Microfinance, social capital and households access to credit: an evidence from Côte d'Ivoire. Structural Change and Economic Dynamics, 23(4), 473-486.

[76] Townsend, R. (1994). Risk and Insurance in Village India. Econometrica, 62, 539-592.

[77] Townsend, P. (1979). Poverty in United Kingdom: A Survey of Household Resources and Standard of living. London: Penguin.

[78] Tesliuc, E. and K. Lindert (2004). Risk and Vulnerability in Guatemala: A Quantitative and Qualitative Assessment.
Social Protection Discussion Paper 408. Washington DC: The World Bank.

[79] Udry, C. (1995). Risk and Saving in Northern Nigeria.

[80] Woolcock, M. and Narayan, D. (2000) Social capital: Implications for development theory, research and policy. World Bank Research Observer 15(2): 225-249.

[81] Whitfield, L. (2005). Trustees of development from conditionality to governance: poverty reduction strategy papers in Ghana. Journal of Modern African Studies, 43 (4): 641-64.

[82] World Bank (2003) "World Bank. 2003. World Development Report 2004 : Making Services Work for Poor People. World Bank. (C) World Bank. https://openknowledge.worldbank.org/handle/10986/5986 License: CC BY 3.0 IGO."

[83] World Bank. (2000). World Development Indicators 2000. Oxford University Press, Oxford United Kingdom.

[84] Wisner B., Blaikie P., Cannon T., Davis I., 1994, 2003, At risk. Natural hazards, people's vulnerability and disasters, Routledge, London, $472 \mathrm{p}$.

[85] Yaqub, S. (2002). Disaster Risk Management and Vulnerability Reduction: Protecting the Poor. Social Protection Workshop 6 : Protecting Communities - Social Funds and Disaster Management. cité par Clark et al., 2010

Author - Ouoya, Doctoral Student, Doctoral School of Economics and Management Department (UFRSEG), Université Félix Houphouet Boigny d'Abidjan, Côie d'Ivoire

Correspondence Author - Ouoya Zrakpa Melaine, ouoyamelaine@yahoo.fr 